\title{
Elasticidade-Renda dos Produtos Alimentares nas Regiões Metropolitanas Brasileiras: Uma Aplicação da POF 1995/1996
}

\author{
- Fernando Gaiger Silveira* \\ - Luís Carlos G. de Magalhães*
}

\author{
- Tatiane A. DE Menezes $* *$ \\ - Bernardo P. Campolina Diniz $* \star \star$
}

\begin{abstract}
RESUMO
$O$ objetivo deste trabalho é estimar a elasticidade-renda para trinta e seis produtos alimentares. A base de dados utilizada é a Pesquisa de Orçamentos Familiares (POF) de 1995/96 do IBGE, que abarca informações extremamente detalhadas sobre o consumo alimentar das famílias das onze maiores regiões urbanas brasileiras. As variáveis utilizadas na estimação do modelo foram obtidas diretamente dos microdados dessa pesquisa. Isto permitiu que os logaritmos dos preços alimentares e do recebimento mensal familiar per capita fossem calculados diretamente das observações individualizadas e não sobre os dados agregados das classes de rendas originais da POF. A metodologia empregada foi o modelo QUAIDS. Os resultados encontrados permitem aprofundar o conhecimento sobre as diferenças do padrão de consumo entre as diversas classes de renda, assim como entre regiões tão distintas como Sudeste e Sul e o Nordeste brasileiro. Evidenciou-se a existência de insuficiência no consumo alimentar domiciliar no Brasil e que tal fato se concentra nas famílias de baixa renda, nas quais as despesas com alimentação respondem pela maior parcela do orçamento.
\end{abstract}

Palavras-CHave

demanda, elasticidade-renda, regiões metropolitanas, cesta CEPAL, modelo AIDS

\section{ABSTRACT}

The aim of this paper is to estimate the income elasticity for thirty-six food commodities. The database used was the Household Budgeting Survey (POF, 1995/96) from IBGE (Brazilian Institute of Geography and Statistics), which has extremely detailed information about consumption in eleven bigger Brazilian urban regions. The variables used in estimation process come from the survey micro-data. This procedure allowed that the logarithms of the prices of food and the monthly per capita familiar income were directly calculated from the individualized observations, instead of aggregate data. The methodology estimation was the QUAIDS model. The results allow deepening the knowledge on the differences of the consumption standards among the diverse income strata, as well as between distinct regions as Southeastern and South and the Brazilian Northeast. It was demonstrated that there is an insufficiency in the domiciliary food consumption in Brazil and that such fact is concentrated in the low-income families, in which the expenditure with foods represents the biggest share of the budget.

\section{KEY WORDS}

demand, income-elasticity, metropolitan regions, ECLAC budget, QUAIDS model

JEL CLASSIFICATION

$R 2 I, Q 1 I, C 2 I, D 2 I$

\footnotetext{
+ Os autores agradecem a valiosas contribuições dadas pelo prof. Rodolfo Hoffmann, do Instituto de Economia da Unicamp. Os eventuais equívocos remanescentes são de responsabilidade dos autores.

* Pesquisadores do IPEA-DISET (Brasília) E-mail: gaiger@ipea.gov.br, Icgarcia@ipea.gov.br.

** Profa. Universidade Federal de Pernambuco e Pesquisadora da FIPE. E-mail: tatianedemenezes@pesquisador.cnpq.br.

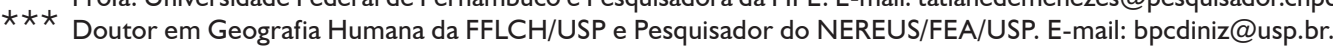

Endereço para contato: SBS - Quadra I - Bloco J - Ed. BNDES, sala 1427 - 140 andar 70076-900 - Brasília - DF.

(Recebido em maio de 2005. Aceito para publicação em agosto de 2006).
} 


\section{INTRODUÇÃO}

Os gastos com alimentos das famílias brasileiras têm sido afetados pelas alterações na renda e em sua distribuição, pelos preços relativos dos bens disponíveis, assim como por outras transformações estruturais ocorridas na sociedade brasileira. Entre estas, podem ser citadas as associadas à urbanização e ao estilo de vida, as mudanças demográficas e da composição das famílias, e ainda do nível educacional e do sexo do chefe da unidade familiar. ${ }^{1}$

É de se esperar, como postula a Lei de Engel, que o processo de desenvolvimento econômico-social acarrete uma redução do peso da alimentação no gasto total das famílias. No entanto, em determinadas regiões do País, e para famílias de menor renda, o gasto com alimentação ainda é aquele de maior peso no orçamento familiar.

Castro e Magalhães (1998, p. 29-30), ao analisarem a evolução da estrutura de gastos familiares a partir dos dados das Pesquisas de Orçamentos Familiares (POF) do IBGE, mostram uma redução da participação dos gastos com alimentação, para o total das áreas pesquisadas e para o conjunto das famílias, de 25,3\% para 23,6\% entre 1987/1988 e 1995/96. Entretanto, para as famílias de Fortaleza que recebiam até dois salários mínimos, cerca de $50 \%$ de seus gastos com consumo eram destinados a alimentos, ou seja, praticamente a metade das despesas de consumo dessas famílias em 1995/96 era comprometida com alimentação. Uma família da mesma classe de renda, moradora em São Paulo, destinava 32,4\% do seu gasto de consumo com alimentos.

Na medida em que os gastos com alimentação ainda são um item fundamental no orçamento das famílias de menor renda, principalmente nas regiões mais pobres do País, estudos sobre demanda de alimentos ganham grande importância no sentido de orientar a formulação de políticas públicas voltadas para a melhoria da segurança alimentar e das condições de nutrição dessa população.

Um conjunto de trabalhos tem estudado o consumo e os gastos com alimentos das famílias brasileiras a partir da estimação de modelos econométricos. A fonte de dados predominantemente utilizada tem sido a POF de 1995/96 do IBGE.

Hoffmann (2000a, b) estima as elasticidades-renda das despesas com alimentos para as grandes regiões urbanas pesquisadas pela POF via estimação por mínimos quadrados ponderados de um modelo poligonal, ajustando os logaritmos das despesas familiares per capita com várias categorias de alimentos contra os logaritmos dos recebimentos

l Para uma avaliação econométrica do efeito de variáveis como tamanho e tipo da família, instrução e sexo do chefe, ver Bertasso (2000). Uma análise das tendências recentes de consumo de alimentos que incorpora essas diferentes dimensões para o caso da Grande São Paulo encontra-se em Cyrillo et al. (1997). 
familiares per capita. O comportamento das elasticidades-renda das despesas estimadas para determinados alimentos, como arroz e feijão, foi diferente do esperado. Os valores estimados foram negativos para os estratos de renda intermediária e positiva nos estratos de renda mais elevada. Outra limitação é que o modelo econométrico utilizado não é deduzido de uma estrutura de preferência do consumidor. Hoffmann (2000a) utiliza o mesmo modelo poligonal para estimar a elasticidade-renda da quantidade consumida de alimentos. Os resultados obtidos apontam para a existência de variações na qualidade de alguns produtos alimentares em função do grau de riqueza das famílias.

Bertasso (2000) estimou a função consumo de grupos de alimentos pelo procedimento de Heckman, com o objetivo de analisar padrões de gastos das famílias brasileiras com esses produtos. Utilizou os microdados da POF de 1995/96. Também ajustou um modelo poligonal às médias de 10 estratos de renda. No caso de refrigerantes, enlatados e alimentos preparados, não foi comprovada a hipótese de seleção amostral, e as elasticidades-renda das despesas foram baixas. As estimativas do modelo poligonal não confirmaram o comportamento esperado para os refrigerantes, os enlatados e conservas e os alimentos consumidos fora do domicílio. Os coeficientes individuais não foram significativos em determinado segmento da polinomial para esses produtos e para outros alimentos fora do domić́lio. As elasticidades estimadas pelo procedimento de Heckman foram sistematicamente menores do que pelas médias dos estratos de renda. $\mathrm{O}$ trabalho não estimou as elasticidades-preço de demanda.

A contribuição desses trabalhos tem sido relevante para a compreensão dos padrões de consumo de alimentos pelas famílias brasileiras e na tentativa de gerar estimativas atualizadas de elasticidades-renda de demanda para esses produtos. No entanto, a especificação das funções a serem estimadas não é deduzida de um modelo completo da estrutura de preferência dos consumidores. Dessa forma, uma variável importante, como o preço dos produtos, fica ausente na explicação do consumo familiar de alimentos.

O objetivo principal desse trabalho é estimar a elasticidade-renda para 39 produtos alimentares, a partir da expansão quadrática do modelo Almost Ideal Demand System (AIDS). ${ }^{2} \mathrm{O}$ modelo aplicado baseia-se no trabalho de Blundell, Pashardes e Weber (1993). Esses autores introduzem uma abordagem inovadora, ao utilizarem

2 Esse modelo foi desenvolvido originalmente por Deaton e Muellbauer (1980). Para uma discussão sintética acerca das vantagens teóricas e econométricas desse modelo, assim como suas restrições, ver Deaton e Muellbauer (1982, p. 75 a 78). São relativamente inexistentes trabalhos que utilizam esse modelo para analisar a demanda de alimentos para o Brasil. Uma exceção é o trabalho de Thomas, Strauss e Barbosa (1989), que utiliza as informações do Endef de 1974/75. Asano e Fiuza (2001) estimam um modelo AIDS para sete grupos de gastos, porém os autores não desagregam os gastos com alimentos. 
uma metodologia de painel aplicada aos microdados da pesquisa de orçamento familiar inglesa.

A base de dados utilizada é a Pesquisa de Orçamentos Familiares de 1995/96 do IBGE, que abarca informações extremamente detalhadas sobre o consumo alimentar das famílias das onze maiores regiões urbanas brasileiras. As variáveis utilizadas na estimação do modelo foram obtidas diretamente dos microdados dessa pesquisa. Isto permitiu que os logaritmos dos preços alimentares e do recebimento mensal familiar per capita fossem calculados diretamente das observações individualizadas e não sobre os dados agregados das classes de rendas originais da POF.

O trabalho está organizado da seguinte forma. O item 1 apresenta a metodologia, na qual se discute o modelo teórico e os procedimentos econométricos adotados para sua estimação e inferência. No item 2 apresenta-se a construção da base de dados a partir dos microdados da POF de 1995/96 do IBGE. Os resultados são analisados no item 3. Por fim, apresentam-se as principais conclusões do estudo e algumas sugestões para aprimorar os resultados obtidos.

\section{METODOLOGIA}

Esta seção apresenta os principais aspectos teóricos do modelo a ser estimado. Discutem-se também os procedimentos econométricos adotados para sua estimação e inferência.

\subsection{Especificação das Preferências Familiares}

Em trabalho clássico - An Almost Ideal Demand System (AIDS) - Deaton e Muellbauer (1980) propõem uma forma funcional para a demanda e a aplicam na derivação de uma função demanda para a Inglaterra. Posteriormente, Blundell, Pashardes e Weber (1993) apresentam uma expansão quadrática do modelo anterior (QUAIDS). Em ambas as formulaçôes a estrutura de demanda é calculada admitindo que as preferências estejam relacionadas no tempo.

No presente trabalho, adaptou-se o modelo de Blundell, Pashardes e Weber (1993) para uma perspectiva espacial. No trabalho, os autores estimam uma função demanda para a Inglaterra como um todo, ao longo de vários anos. $\mathrm{Na}$ abordagem aqui desenvolvida, a estimação da função demanda capta o comportamento das famílias para diferentes regiôes e distintas faixas de renda para um único período de tempo, sendo 
calculada a demanda por produtos alimentícios entre as 11 regióes metropolitanas brasileiras, tendo por base os microdados da POF de 1995-96.

Os produtos considerados diretamente no modelo compóem a cesta de bens q e são os 39 itens da cesta de alimentos citados na Tabela 1. Os demais produtos que compõem os gastos das famílias assim como as características regionais são representados no modelo pela letra z. Embora o consumo relativo do primeiro grupo dependa do segundo, as preferências entre os dois grupos são fracamente separadas. Uma vez que a função demanda é consistente na agregação, é possível estimar individualmente seus componentes, sendo que no presente caso foi estimada a demanda por produtos alimentícios.

A hipótese do modelo é que as famílias decidem previamente quanto vão alocar de sua renda para gastos com a cesta q e quanto fica disponível para gastos com os outros produtos presentes em $\mathbf{z}$. Tal decisão é considerada exógena e só após ter sido tomada é que as famílias irão alocar seus gastos com os 39 itens que pertencem à cesta q. As preferências da família $h$ são tais que, em cada período $t$, na cidade $l$, cada família toma a decisão de quanto consumir de uma cesta de bens q condicional aos produtos do grupo z. Assume-se, ainda, que $q^{h}{ }_{i l}$ representa a quantidade consumida do bem $i$ pela família $h$ na cidade $l$, e que $m^{h}{ }_{l}$ corresponde aos gastos da família $h$ com a cesta de bens q na cidade $l$. Os gastos com o bem $i$ para um dado $z_{l}^{h}$ podem ser expressos como:

$$
p_{i l} q_{i l}^{h}=f_{i}\left(\mathbf{p}_{l}, m_{l}^{h} ; \mathbf{z}_{l}^{h}\right)
$$

em que $f_{i}$ descreve as preferências em cada cidade e $\mathbf{p}_{l}$ é o vetor de preços nesta determinada cidade. Sob a hipótese de fraca separabilidade das preferências, e conhecendo $\mathrm{m}^{h}{ }$, é possível estabelecer o valor para cada $f_{i}$ sem que haja a necessidade de se conhecer os preços e os gastos com os outros produtos nas demais cidades.

As preferências de cada família são descritas abstraindo-se o fato de que existem distintas características entre as regiões. Desta forma, admitindo-se que as famílias são maximizadoras de utilidade. e trabalhando com a função utilidade indireta (Marshalliana), a participação do bem $i$ na renda da família $h$ na cidade $l$ é dada por:

$$
s_{i l}^{h}=\alpha_{0}+\sum_{l} \gamma_{j i} \ln p_{j l}+\beta_{i l}^{h} \ln x_{l}^{h}+\lambda_{i l}^{h}\left(\ln x_{l}^{h}\right)^{2}
$$

em que $x^{h}$ lé a renda da família $h$ na cidade $l$. A equação (2) consiste no modelo QUAIDS e encontra-se derivada em Blundell, Pashardes e Weber (1993).

O modelo acima foi agregado para $k$ faixas de renda $(k=1,2, \ldots, 10)$. Os gastos totais da faixa de renda $k$, com a cesta $\mathbf{q}$ na cidade $l$, são representados por $M_{k l}\left(\sum_{h} m^{h}{ }_{k l}\right)$ 
e $\mu^{h}{ }_{k l}=\left(m^{h}{ }_{k l} / M_{k l}\right)$, que é a participação dos gastos da família $h$ nos gastos totais das famílias da faixa de renda $k$ da cidade $l$. Multiplicando $s^{h}{ }_{i l}$ por $\mu^{h}{ }_{k l}$, encontra-se a participação do bem $i$ na renda, para a faixa de renda $k$ da cidade $l$, $s_{i k l}$. Por conseguinte, o equivalente agregado da forma funcional (2) pode ser expresso como:

$$
s_{i k l}=\alpha_{0}+\sum_{j} \gamma_{j i} \ln p_{j l}+\beta_{i l} \sum_{h} \mu_{k l}^{h} \ln x_{l}^{h}+\lambda_{i l} \sum_{h} \mu_{k l}^{h}\left(\ln x_{l}^{h}\right)^{2}
$$

A equação (3) pode ser estimada como abaixo:

$$
s_{i k l}=\alpha_{0}+\sum_{j} \gamma_{j i} \ln p_{j l}+\beta_{i l} \pi_{0 k l} \ln X_{k l}+\lambda_{i l} \pi_{1 k l}\left(\ln X_{k l}\right)^{2}
$$

em que $\ln X_{k l}$ é a média do ln neperiano da renda familiar per capita para cada faixa de renda. Para verificar a consistência dos parâmetros após o processo de agregação observa-se que:

$$
\begin{aligned}
& \pi_{0 k l}=\sum_{h} \mu_{k l}^{h} \ln x_{l}^{h} / \ln X_{k l} \\
& \pi_{1 k l}=\sum_{h} \mu_{k l}^{h}\left(\ln x_{l}^{h}\right)^{2} /\left(\ln X_{k l}\right)^{2}
\end{aligned}
$$

Desde que os fatores de agregação (5a) e (5b) sejam aproximadamente constantes entre as $l$ cidades, $\pi_{j l}$ fica bem próximo da unidade, de modo que os parâmetros da equação (4) podem ser consistentemente estimados.

\subsection{Procedimentos Econométricos}

Com base nas equações (4), (5a) e (5b) foram construídos os modelos (6) e (7) a serem estimados.

$$
\begin{aligned}
& s_{i k l}=\alpha_{0}+\sum_{j} \gamma_{j i} \ln p_{j l}+\beta_{i l} \ln Y_{k l}+\lambda_{i l}\left(\ln Y_{k l}\right)^{2}+e_{i k l} \\
& s_{i k l}=\sum_{j} \gamma_{j i} \ln p_{j l}+\beta_{i l}^{*}\left(\ln Y_{k l} * R M\right)+\lambda_{i l}^{*}\left[\left(\ln Y_{k l}\right)^{2} * R M\right]+e_{i k l}
\end{aligned}
$$

Os modelos (6) e (7) foram estimados para cada um dos 39 produtos por Mínimos Quadrados Ordinários (MQO). ${ }^{3}$ Os dados consistem em uma cross-section, cujas observações estão disponíveis para 10 grupos de renda nas 11 regiões metropolitanas

3 A relação desses produtos é feita a seguir, constando da Tabela 1, anexa. 
da POF. No modelo (6) os coeficientes do logaritmo da renda e do seu quadrado permitem calcular a elasticidade renda dos produtos da cesta. No modelo (7) o logaritmo neperiano da renda e seu quadrado foram multiplicados pelas dummies de região metropolitana, sendo os coeficientes desta interação utilizados para estimar a elasticidade-renda da cesta para as regióes metropolitanas brasileiras.

Uma questão que pode surgir é se os gastos são uma boa proxy para o consumo. Caso não sejam, tal discrepância estaria influenciando tanto a variável dependente como a renda, o que seria uma fonte de endogeneidade no modelo, tornando os estimadores enviesados. Quando se trabalha com grupos de produtos cuja aquisição não é freqüente, como eletrodomésticos, esta preocupação é válida. No caso de gêneros alimentícios, entretanto, sua aquisição é contínua, de modo que a distância entre gastos e consumo pode ser desconsiderada. ${ }^{4}$

No modelo, os preços variam entre as 10 faixas de renda e as 11 regióes metropolitanas para cada equação de participação estimada. Além disto, como esperado, a correlação entre eles é muito alta. Ambos os fatores aumentam o erro padrão da regressão, diminuindo a eficiência do teste $t$. Uma forma de contornar este problema é via realização do teste $F$ de significância conjunta. Com este teste é possível verificar se o coeficiente do preço do produto, assim como de seus substitutos e complementares, o logaritmo da renda e o quadrado do logaritmo da renda são conjuntamente significantes no modelo. Os resultados das estimativas são discutidos no item 3 do trabalho.

\section{BASE DE DADOS}

A Pesquisa de Orçamentos Familiares (POF) 1995-96, do IBGE, foi a fonte das informações dos dispêndios e dos rendimentos utilizadas no cálculo das elasticidadesrenda dos produtos alimentares. A POF 1995-96 cobriu um período de doze meses, entre primeiro de outubro de 1995 e trinta de setembro de 1996, tendo como data de referência 15 de setembro de 1996, quando o salário mínimo era de R \$112,00 (cento e doze reais). 16.060 famílias fizeram parte da amostra da POF 1995-96, sendo que a mesma foi desenhada de modo a representar as características gerais da população, tais como instrução, renda, tamanho, perfil etário etc.

Os dispêndios da POF 1995-96 foram pesquisados por meio de três instrumentos de coleta: dois questionários de despesa e uma caderneta de despesa coletiva. Os dois

4 Uma vez que os gastos com alimentos na POF têm por base uma semana de referência, eles apresentam descontinuidade. Entretanto, como eles são agregados entre famílias semelhantes, tal problema deixa de existir. 
questionários abrangeram as despesas coletivas e as despesas individuais, cujas coletas se processaram pela recuperação dos gastos. A caderneta de despesa englobava os gastos familiares com alimentos, bebidas, artigos de higiene pessoal, de limpeza, e outras pequenas compras cotidianas, que deviam ser registrados durante os sete dias consecutivos de coleta dos dados no domić́lio. Nos microdados, contabilizam-se 382.442 aquisições apuradas pela caderneta de despesas, sendo que 235.240 referemse a 41 produtos alimentares, ${ }^{5}$ que constituem versão reduzida da cesta normativa proposta pela CEPAL (1989). Ademais, nos microdados da POF encontram-se 925.952 registros de desembolso, sendo 868.176 de gastos com itens de consumo, dos quais 388.526 são aquisições de alimentos e bebidas, inclusive as relacionadas à alimentação fora do domicílio.

O universo investigado pela POF 1995-96 representa 12,5 milhões de famílias (46,4 milhões de pessoas), localizadas nos onze principais centros urbanos do País. ${ }^{6}$ Segundo a POF, as despesas de consumo das famílias metropolitanas atingiram, em 1996, R\$ 149,4 bilhões, dos quais R\$ 16,1 bilhões com alimentos da cesta. ${ }^{7}$ Notase, portanto, que os gastos com a cesta representam $10,8 \%$ do orçamento familiar. De outra parte, a participação dos registros de aquisição desses produtos no total dos registros de consumo alcança $27,2 \%$. Ou seja, são produtos repetidamente adquiridos pelas famílias.

Observando-se a participação dos gastos com a cesta no dispêndio familiar segundo as classes de renda em salários mínimos, disponibilizadas pelo plano tabular do IBGE, fica evidente o quão importante eles são para as famílias de menor renda. Para estas, os gastos com os produtos da cesta representam cerca de um quarto das despesas de consumo. Quanto à participação dos gastos com a cesta no total do dispêndio alimentar (considerando bebidas e alimentação fora do domić́lio), estes representam, na média das classes e no total das áreas, quase $50 \%$. As despesas totais com alimentos da cesta variam entre $30,9 \%$ e $65,8 \%$ do total da despesa com alimentos, respectivamente para famílias com renda mensal superior a 30 salários mínimos e para aquelas com renda de até dois salários mínimos.

Outro ponto importante é que, dentre as aquisiçóes com produtos da cesta, ocorre um número expressivo de registros que constam de informações tanto de gasto como de

5 Perfazem a cesta de alimentos selecionados: açúcar, alho, arroz, banana, batata, biscoito doce, biscoito salgado, café, carne bovina de primeira, carne bovina de segunda, carne de suíno, cebola, couve, farinha de mandioca, farinha de trigo, fígado, feijão, frango, iogurte, laranja, leite, leite em pó, limão, lingüiça, macarrão, maionese, mandioca, manteiga, margarina, massa de tomate, óleos, pão francês, presunto, queijos, repolho, sal, salsicha, tomate, ovos, peixe, mortadela.

6 São as seguintes as áreas pesquisadas: as regiões metropolitanas de Porto Alegre, Curitiba, São Paulo, Rio de Janeiro, Belo Horizonte, Salvador, Recife, Fortaleza e Belém, mais o município de Goiânia e Brasília.

7 Em valores de setembro de 1996, para o período compreendido entre $1^{\circ}$ de outubro de 1995 e 30 de setembro de 1996. 
quantidade adquirida. Especificamente, das 235 mil aquisições de produtos da cesta, cerca de três quartos apresentam discriminação de gastos e quantidades, possibilitando calcular os preços pagos nas compras das famílias. De outra parte, quando se passa do conjunto dos produtos da cesta para o total das despesas alimentares, as aquisições com preços e aquelas sem preço - seja devido à ausência de quantidade e/ou do gasto - são significativamente menores, atingindo pouco mais de dois terços no universo das despesas alimentares. Dito de outra forma, além desta cesta de produtos contemplar a maior parcela do gasto com alimentação, grande parte dos registros de aquisições com esses produtos permite o cálculo dos seus preços.

Verificou-se que dentre os $4 \mathrm{l}$ produtos, ovos e couve não apresentavam nenhuma informação quanto à quantidade adquirida; por este motivo, decidiu-se retirá-los da cesta de produtos. Assim, restaram 227.497 aquisições, sendo que 183.410 continham o valor da compra e a quantidade adquirida. Retirando as famílias que não declararam renda e agregando-se as despesas realizadas com os mesmos produtos, pela mesma família, na semana de referência, chegou-se a um total de 115.786 aquisições. Decidiuse, por fim, excluir alguns locais de compra cuja frequiência de aquisições era inferior a $15 \%$ do total. Com esse conjunto de dados, calcularam-se os preços implícitos pela razão entre gastos e quantidades. Os preços médios empregados no modelo foram estimados com base nesta amostra de 113.867 aquisiçóes, correspondente às despesas efetuadas por 14.922 famílias.

A construção da estrutura de ponderação e das faixas de renda foi feita com base no conjunto de famílias que declararam ter algum rendimento, base esta que se constitui de 16.024 famílias. Com esta subamostra foram construídos dez estratos populacionais, de igual tamanho, para cada um dos centros urbanos. O passo seguinte constituiu em subdividir a população de cada área segundo a renda familiar per capita.

O modelo Weight Country Product Dummy (WCPD) foi empregado para a estimação dos preços médios de cada produto, por faixa de renda e região metropolitana. Este método foi desenvolvido por Kravis, Heston e Summers (1982) e Selvanathan e Rao (1994), sendo empregado internacionalmente para comparar a Paridade do Poder de Compra entre países e entre regiões de um mesmo país. No Brasil, foi utilizado por Aten (1999) para comparar preços de gêneros alimentícios entre regiões metropolitanas brasileiras para os anos de 1984 a 1987, tendo também sido empregado por Menezes e Azzoni (2006) e Azzoni et al. (2003) para a construção de uma PPP regional e por Aten e Menezes (2002) para calcular o diferencial de custo de vida por faixa de renda.

Neste trabalho, o modelo não foi empregado com o objetivo de comparar níveis de preços, mas sim para a construção de preços médios a serem aplicados na estimação das elasticidades. Abaixo, descreve-se a especificação: 
$\ln P=\alpha_{1}\left(H_{1} * R_{1} * I N C_{1}\right)+\alpha_{2}\left(H_{2} * R_{1} * I N C_{1}\right)+\ldots+\alpha_{39}\left(H_{39} * R_{1} * I N C_{1}\right)+\alpha_{40}\left(H_{1} * R_{2} * I N C_{1}\right)+$ $+\alpha_{41}\left(H_{36} * R_{2} * I N C_{1}\right)+\ldots+\alpha_{390}\left(H_{36} * R_{11} * I N C_{1}\right)+\alpha_{391}\left(H_{1} * R_{1} * I N C_{2}\right)+\alpha_{92}\left(H_{1} * R_{1} * I N C_{3}\right)+$ $+\ldots+\alpha_{4289}\left(H_{36} * R_{11} * I N C_{9}\right)$

em que $\ln P$ é o logaritmo neperiano do preço do bem e $\left(\mathrm{H}_{i}{ }^{*} \mathrm{R}_{k}{ }^{*} \mathrm{INC}_{l}\right)$ corresponde à interação entre as 39 dummies produto, $11 \mathrm{RM}$ e nove faixas de renda. A última dummy de interação (que equivale à última faixa de renda em Goiânia) foi retirada da mostra e é utilizada como base. O exponencial dos coeficientes das dummies de interação corresponde ao preço médio de cada um dos 39 produtos da cesta, nas 11 RMs e as nove faixas de renda.

O modelo foi estimado por Mínimos Quadrados Ponderados (MQP), em que a matriz dos pesos é dada pela quantidade adquirida total ${ }^{8}$ de cada produto. Observou-se que para três produtos havia muitas lacunas de preços, decidindo-se, então, não estimar suas elasticidades. ${ }^{9}$ Foram calculadas as elasticidades para os 36 produtos restantes.

As informações das participações dos gastos com cada produto na renda segundo as faixas e por regióes metropolitanas foram calculadas considerando todas as famílias que declararam terem renda. A utilização dos grupos de renda é justificada com base nas próprias características do processo de amostragem e coleta de informações da POF. ${ }^{10} \mathrm{O}$ acompanhamento semanal das despesas alimentares durante um ano visa coletar, de modo mais preciso, os hábitos alimentares das famílias, minimizando o comportamento sazonal dos gastos alimentares. Na medida em que a coleta das informações exige um período de tempo longo, não é factível manter uma mesma família como informante. Realiza-se, portanto, uma rotação da amostra, ou seja, procura-se investigar unidades de consumo (famílias) representativas com características se não idênticas, pelo menos muito semelhantes, durante um ano, embora a unidade de coleta não seja a mesma. Desta forma, as observações individualizadas das unidades de consumo (famílias) referentes aos gastos alimentares apresentam inúmeras situações-limite, como, por exemplo, famílias investigadas na semana da compra mensal e famílias com poucas aquisições ou mesmo nenhuma (que apresentavam, por exemplo, estoques alimentares de produtos menos perecíveis).

Uma forma de contornar os problemas discutidos acima é trabalhar com as informações de compras de alimentos pelas famílias de forma mais agregada. ${ }^{11}$ Como a renda é a variável utilizada na seleção e na rotação da amostra de domićlios a serem investigados, decidiu-se utilizá-la como variável de agrupamento das famílias. Dividiu-se, assim, a população - total de pessoas - em 10 faixas ordenadas por recebimento familiar per capita.

8 Refere-se à multiplicação da quantidade pelo fator de expansão da amostra e pelo número de componentes da família.

9 Iogurte, limão e repolho foram os produtos retirados. Restaram, então, poucos casos, para os quais não existiam preços, utilizando-se então a média do preço na região metropolitana.

10 Para mais detalhes, ver Bianchini e Albieri (1999).

11 Outra alternativa é utilizar o procedimento de seleção amostral, como Bertasso (2001). 
Na Tabela 1 encontram-se as variáveis utilizadas na estimativa das elasticidades e seus respectivos valores médios, mínimos e máximos referentes aos dados médios das 110 novas observações, resultantes da agregação dos dados individualizados em 10 grupos de renda em onze regióes metropolitanas.

TABELA 1 - VALORES MÉDIO, MÍNIMO E MÁXIMO E DESVIOS PADRÓES DAS VARIÁVEIS DO MODELO - TOTAL DAS ÁREAS. POF 1995-96

\begin{tabular}{|c|c|c|c|}
\hline Participações do gasto no recebimento & Média & Mínimo & Máximo \\
\hline Açúcar & 0,0057 & 0,0002 & 0,0302 \\
\hline Alho & 0,0007 & 0,0000 & 0,0040 \\
\hline Arroz & 0,0100 & 0,0003 & 0,0565 \\
\hline Banana & 0,0026 & 0,0003 & 0,0117 \\
\hline Batata & 0,0026 & 0,0002 & 0,0186 \\
\hline Biscoito Doce & 0,0032 & 0,0005 & 0,0162 \\
\hline Biscoito Sal & 0,0025 & 0,0002 & 0,0144 \\
\hline Café & 0,0060 & 0,0003 & 0,0344 \\
\hline Carne de $1^{\mathrm{a}}$ & 0,0130 & 0,0020 & 0,0506 \\
\hline Carne de $2^{\mathrm{a}}$ & 0,0107 & 0,0003 & 0,0911 \\
\hline Suíno & 0,0016 & 0,0000 & 0,0142 \\
\hline Cebola & 0,0010 & 0,0001 & 0,0056 \\
\hline Farinha de Mandioca & 0,0020 & 0,0000 & 0,0556 \\
\hline Farinha de Trigo & 0,0011 & 0,0000 & 0,0101 \\
\hline Feijão & 0,0063 & 0,0001 & 0,0440 \\
\hline Fígado & 0,0010 & 0,0000 & 0,0097 \\
\hline Frango & 0,0142 & 0,0009 & 0,0913 \\
\hline Laranja & 0,0019 & 0,0002 & 0,0096 \\
\hline Leite & 0,0147 & 0,0006 & 0,0560 \\
\hline Leite em pó & 0,0059 & 0,0000 & 0,0583 \\
\hline Lingüiça & 0,0020 & 0,0000 & 0,0072 \\
\hline Macarrão & 0,0031 & 0,0002 & 0,0165 \\
\hline Maionese & 0,0005 & 0,0000 & 0,0024 \\
\hline Mandioca & 0,0004 & 0,0000 & 0,0056 \\
\hline Manteiga & 0,0008 & 0,0000 & 0,0042 \\
\hline Margarina & 0,0022 & 0,0001 & 0,0129 \\
\hline Massa de Tomate & 0,0010 & 0,0000 & 0,0050 \\
\hline Óleos & 0,0039 & 0,0004 & 0,0169 \\
\hline Pão & 0,0215 & 0,0012 & 0,1184 \\
\hline Presunto & 0,0006 & 0,0000 & 0,0032 \\
\hline Queijos & 0,0022 & 0,0002 & 0,0116 \\
\hline Sal & 0,0004 & 0,0000 & 0,0026 \\
\hline Salsicha & 0,0012 & 0,0000 & 0,0056 \\
\hline Tomate & 0,0020 & 0,0002 & 0,0131 \\
\hline Peixe & 0,0037 & 0,0000 & 0,0459 \\
\hline Mortadela & 0,0008 & 0,0000 & 0,0052 \\
\hline
\end{tabular}




\begin{tabular}{|c|c|c|c|}
\hline Preços ( $\mathrm{R} \$$ de setembro de 1996) & Média & Mínimo & Máximo \\
\hline Açúcar & 0,5308 & 0,3897 & 0,6269 \\
\hline Alho & 4,9694 & 0,0000 & 9,9000 \\
\hline Arroz & 0,6829 & 0,5369 & 0,8425 \\
\hline Banana & 0,7086 & 0,0000 & 1,8260 \\
\hline Batata & 0,6939 & 0,4455 & 1,0245 \\
\hline Biscoito Doce & 3,5374 & 2,4510 & 4,7018 \\
\hline Biscoito Sal & 3,1654 & 2,2987 & 5,5575 \\
\hline Café & 5,1736 & 4,3414 & 6,4072 \\
\hline Carne de $1^{\mathrm{a}}$ & 3,6930 & 2,8649 & 4,4521 \\
\hline Carne de $2^{\mathrm{a}}$ & 2,3533 & 1,4904 & 2,8477 \\
\hline Suíno & 2,7674 & 0,0000 & 4,4600 \\
\hline Cebola & 0,5192 & 0,3205 & 0,9574 \\
\hline Farinha de Mandioca & 0,6025 & 0,0000 & 0,9285 \\
\hline Farinha de Trigo & 0,7494 & 0,5364 & 1,1844 \\
\hline Feijão & 1,0727 & 0,7039 & 1,3758 \\
\hline Fígado & 2,2579 & 0,0000 & 3,5500 \\
\hline Frango & 1,6132 & 1,1554 & 2,0337 \\
\hline Laranja & 0,3492 & 0,0000 & 2,0496 \\
\hline Leite & 0,7777 & 0,6287 & 1,2420 \\
\hline Leite em pó & 6,9840 & 0,0000 & 12,7751 \\
\hline Lingüiça & 3,2729 & 0,0000 & 5,1042 \\
\hline Macarrão & 1,5170 & 1,0635 & 2,1727 \\
\hline Maionese & 3,8094 & 0,0000 & 5,8649 \\
\hline Mandioca & 0,6719 & 0,0000 & 1,5510 \\
\hline Manteiga & 4,4748 & 0,0000 & 9,4000 \\
\hline Margarina & 3,0701 & 2,4290 & 4,0522 \\
\hline Massa de Tomate & 4,0567 & 0,0000 & 8,6667 \\
\hline Óleos & 1,0916 & 0,8405 & 2,0209 \\
\hline Pão & 2,2602 & 1,8658 & 2,6648 \\
\hline Presunto & 6,0952 & 0,0000 & 12,0000 \\
\hline Queijos & 5,7619 & 0,0000 & 8,6580 \\
\hline Sal & 0,3342 & 0,2178 & 0,4900 \\
\hline Salsicha & 2,1468 & 0,0000 & 3,2000 \\
\hline Tomate & 0,8141 & 0,5059 & 1,1626 \\
\hline Peixe & 2,7936 & 0,9505 & 7,7958 \\
\hline Mortadela & 2,8307 & 0,0000 & 4,6585 \\
\hline Renda & 442,74 & 19,18 & 2439,58 \\
\hline
\end{tabular}

Fonte:Elaboração própria a partir dos microdados da POF 1995/96.

\section{RESULTADOS DA ESTIMAÇÃO E CÁLCULO DAS ELASTICIDADES}

Nesta seção discutem-se os resultados obtidos com o procedimento de estimação anteriormente descrito, assim como os testes sobre os parâmetros estimados. 


\subsection{Estimação e Inferência do Modelo}

Inicialmente foram estimados os modelos (6) e (7) para cada um dos produtos da cesta. A Tabela 2 apresenta os coeficientes estimados para a renda e seu quadrado, com e sem a cidade de Goiânia fazendo parte da amostra. As manipulações da base assim como a análise dos resultados mostram algumas incongruências. Tais problemas surgem, principalmente, por ser esta a cidade com maior número de informações faltantes, quase três vezes mais do que a média total de dados inexistentes, $0,7 \%$ para a amostra e 1,9\% para Goiânia. Por conseguinte, foi nesta cidade onde se imputou o maior número de observações. Optou-se, assim, por calcular a elasticidade-renda em duas situações: a primeira com a amostra completa e a segunda exclusive Goiânia.

TABELA 2 - COEFICIENTES ESTIMADOS PARA OS PARÂMETROS DA RENDA E RENDA AO QUADRADO PARA O BRASIL E BRASIL EXCLUSIVE GOIÂNIA

\begin{tabular}{|c|c|c|c|c|c|c|}
\hline \multirow{2}{*}{ Produtos } & \multicolumn{3}{|c|}{ Brasil $(n=110)$} & \multicolumn{3}{|c|}{ Brasil s/ Goiânia (n=100) } \\
\hline & LY & $L Y^{2}$ & R2 & LY & $L Y^{2}$ & R2 \\
\hline Açúcar & $\begin{array}{r}-0,0232 \\
(0,0018)\end{array}$ & $\begin{array}{r}0,0017 \\
(0,0002)\end{array}$ & 0,95 & $\begin{array}{r}-0,0251 \\
(0,0017)\end{array}$ & $\begin{array}{r}0,0018 \\
(0,0002)\end{array}$ & 0,97 \\
\hline Alho & $\begin{array}{r}-0,0017 \\
(0,0005)\end{array}$ & $\begin{array}{r}0,0001 \\
(0,0000)\end{array}$ & 0,73 & $\begin{array}{r}-0,00153 \\
(0,0005)\end{array}$ & $\begin{array}{r}0,0001 \\
(0,0000)\end{array}$ & 0,75 \\
\hline Arroz & $\begin{array}{r}-0,0323 \\
(0,0043)\end{array}$ & $\begin{array}{r}0,0022 \\
(0,0004)\end{array}$ & 0,91 & $\begin{array}{r}-0,0293 \\
(0,0051)\end{array}$ & $\begin{array}{r}0,0019 \\
(0,0004)\end{array}$ & 0,91 \\
\hline Banana & $\begin{array}{r}-0,0035 \\
(0,0009)\end{array}$ & $\begin{array}{r}0,0002 \\
(0,0001)\end{array}$ & 0,86 & $\begin{array}{r}-0,0028 \\
(0,0010)\end{array}$ & $\begin{array}{r}0,0001 \\
(0,0001)\end{array}$ & 0,86 \\
\hline Batata & $\begin{array}{r}-0,0048 \\
(0,0021)\end{array}$ & $\begin{array}{r}0,0003 \\
(0,0002)\end{array}$ & 0,68 & $\begin{array}{r}-0,0052 \\
(0,0022)\end{array}$ & $\begin{array}{r}0,0003 \\
(0,0002)\end{array}$ & 0,72 \\
\hline Biscoito doce & $\begin{array}{r}-0,0077 \\
(0,0015)\end{array}$ & $\begin{array}{r}0,0005 \\
(0,0001)\end{array}$ & 0,88 & $\begin{array}{r}-0,0084 \\
(0,0018)\end{array}$ & $\begin{array}{r}0,0006 \\
(0,0002)\end{array}$ & 0,89 \\
\hline Biscoito salgado & $\begin{array}{r}-0,0083 \\
(0,0013)\end{array}$ & $\begin{array}{r}0,0005 \\
(0,0001)\end{array}$ & 0,91 & $\begin{array}{r}-0,0090 \\
(0,0012)\end{array}$ & $\begin{array}{r}0,0006 \\
(0,0001)\end{array}$ & 0,93 \\
\hline Café & $\begin{array}{c}-0,0234 \\
(0,0025)\end{array}$ & $\begin{array}{r}0,0017 \\
(0,0002)\end{array}$ & 0,94 & $\begin{array}{r}-0,0257 \\
(0,0025)\end{array}$ & $\begin{array}{r}0,0019 \\
(0,0002)\end{array}$ & 0,95 \\
\hline Carne de $1^{a}$ & $\begin{array}{r}-0,0045 \\
(0,0034)\end{array}$ & $\begin{array}{r}-0,0001 \\
(0,0003)\end{array}$ & 0,83 & $\begin{array}{r}-0,0036 \\
(0,0043)\end{array}$ & $\begin{array}{r}-0,0001 \\
(0,0004)\end{array}$ & 0,85 \\
\hline Carne de $2^{\mathrm{a}}$ & $\begin{array}{r}-0,0336 \\
(0,0064)\end{array}$ & $\begin{array}{r}0,0022 \\
(0,0006)\end{array}$ & 0,88 & $\begin{array}{r}-0,0345 \\
(0,0065)\end{array}$ & $\begin{array}{r}0,0024 \\
(0,0006)\end{array}$ & 0,89 \\
\hline Suíno & $\begin{array}{r}-0,0017 \\
(0,0013)\end{array}$ & $\begin{array}{r}0,0001 \\
(0,0001)\end{array}$ & 0,68 & $\begin{array}{r}-0,0017 \\
(0,0016)\end{array}$ & $\begin{array}{r}0,0001 \\
(0,0001)\end{array}$ & 0,68 \\
\hline Cebola & $\begin{array}{r}-0,0027 \\
(0,0004)\end{array}$ & $\begin{array}{r}0,0002 \\
(0,0000)\end{array}$ & 0,89 & $\begin{array}{r}-0,0032 \\
(0,0004)\end{array}$ & $\begin{array}{r}0,0002 \\
(0,0000)\end{array}$ & 0,90 \\
\hline Farinha de Mandioca & $\begin{array}{r}-0,0207 \\
(0,0049)\end{array}$ & $\begin{array}{r}0,0016 \\
(0,0004)\end{array}$ & 0,81 & $\begin{array}{r}-0,0221 \\
(0,0049)\end{array}$ & $\begin{array}{r}0,0018 \\
(0,0004)\end{array}$ & 0,83 \\
\hline Fainha de Trigo & $\begin{array}{r}-0,0022 \\
(0,0009)\end{array}$ & $\begin{array}{r}0,0001 \\
(0,0001)\end{array}$ & 0,72 & $\begin{array}{r}-0,0031 \\
(0,0011)\end{array}$ & $\begin{array}{r}0,0002 \\
(0,0001)\end{array}$ & 0,75 \\
\hline Feijão & $\begin{array}{r}-0,0263 \\
(0,0032)\end{array}$ & $\begin{array}{r}0,0019 \\
(0,0003)\end{array}$ & 0,93 & $\begin{array}{r}-0,0265 \\
(0,0031)\end{array}$ & $\begin{array}{r}0,0019 \\
(0,0003)\end{array}$ & 0,95 \\
\hline
\end{tabular}




\begin{tabular}{|c|c|c|c|c|c|c|}
\hline \multirow{2}{*}{ Produtos } & \multicolumn{3}{|c|}{ Brasil $(n=110)$} & \multicolumn{3}{|c|}{ Brasil s/ Goiânia $(n=100)$} \\
\hline & LY & $L Y^{2}$ & $\mathrm{R} 2$ & LY & $\mathrm{LY}^{2}$ & $\mathrm{R} 2$ \\
\hline Fígado & $\begin{array}{r}-0,0047 \\
(0,0010)\end{array}$ & $\begin{array}{r}0,0003 \\
(0,0001)\end{array}$ & 0,84 & $\begin{array}{r}-0,0052 \\
(0,0012)\end{array}$ & $\begin{array}{r}0,0004 \\
(0,0001)\end{array}$ & 0,85 \\
\hline Frango & $\begin{array}{r}-0,0602 \\
(0,0066)\end{array}$ & $\begin{array}{r}0,0043 \\
(0,0006)\end{array}$ & 0,92 & $\begin{array}{r}-0,0624 \\
(0,0071)\end{array}$ & $\begin{array}{r}0,0045 \\
(0,0006)\end{array}$ & 0,93 \\
\hline Laranja & $\begin{array}{r}-0,0024 \\
(0,0011)\end{array}$ & $\begin{array}{r}0,0002 \\
(0,0001)\end{array}$ & 0,78 & $\begin{array}{r}-0,0024 \\
(0,0011)\end{array}$ & $\begin{array}{r}0,0001 \\
(0,0001)\end{array}$ & 0,81 \\
\hline Leite & $\begin{array}{r}-0,0136 \\
(0,0054)\end{array}$ & $\begin{array}{r}0,0007 \\
(0,0005)\end{array}$ & 0,82 & $\begin{array}{r}-0,0154 \\
(0,0061)\end{array}$ & $\begin{array}{r}0,0009 \\
(0,0006)\end{array}$ & 0,83 \\
\hline Leite em pó & $\begin{array}{r}-0,0329 \\
(0,0050)\end{array}$ & $\begin{array}{r}0,0024 \\
(0,0004)\end{array}$ & 0,91 & $\begin{array}{r}-0,0342 \\
(0,0052)\end{array}$ & $\begin{array}{r}0,0024 \\
(0,0005)\end{array}$ & 0,92 \\
\hline Lingüiça & $\begin{array}{r}-0,0009 \\
(0,0010)\end{array}$ & $\begin{array}{r}0,0000 \\
(0,0001)\end{array}$ & 0,70 & $\begin{array}{r}-0,0013 \\
(0,0012)\end{array}$ & $\begin{array}{r}0,0000 \\
(0,0001)\end{array}$ & 0,72 \\
\hline Macarrão & $\begin{array}{r}-0,0096 \\
(0,0011)\end{array}$ & $\begin{array}{r}0,0007 \\
(0,0001)\end{array}$ & 0,92 & $\begin{array}{r}-0,0101 \\
(0,0014)\end{array}$ & $\begin{array}{r}0,0007 \\
(0,0001)\end{array}$ & 0,93 \\
\hline Maionese & $\begin{array}{r}-0,0007 \\
(0,0003)\end{array}$ & $\begin{array}{r}0,0001 \\
(0,0000)\end{array}$ & 0,69 & $\begin{array}{r}-0,0010 \\
(0,0004)\end{array}$ & $\begin{array}{r}0,0001 \\
(0,0000)\end{array}$ & 0,73 \\
\hline Mandioca & $\begin{array}{r}-0,0008 \\
(0,0009)\end{array}$ & $\begin{array}{r}0,0001 \\
(0,0001)\end{array}$ & 0,62 & $\begin{array}{r}-0,0010 \\
(0,0009)\end{array}$ & $\begin{array}{r}0,0001 \\
(0,0001)\end{array}$ & 0,66 \\
\hline Manteiga & $\begin{array}{r}-0,0005 \\
(0,0005)\end{array}$ & $\begin{array}{r}0,0000 \\
(0,0000)\end{array}$ & 0,67 & $\begin{array}{r}-0,0004 \\
(0,0006)\end{array}$ & $\begin{array}{r}0,0000 \\
(0,0000)\end{array}$ & 0,70 \\
\hline Margarina & $\begin{array}{r}-0,0080 \\
(0,0009)\end{array}$ & $\begin{array}{r}0,0006 \\
(0,0001)\end{array}$ & 0,94 & $\begin{array}{r}-0,0088 \\
(0,0009)\end{array}$ & $\begin{array}{r}0,0006 \\
(0,0001)\end{array}$ & 0,95 \\
\hline Massa de Tomate & $\begin{array}{r}-0,0016 \\
(0,0006)\end{array}$ & $\begin{array}{r}0,0001 \\
(0,0001)\end{array}$ & 0,72 & $\begin{array}{r}-0,0016 \\
(0,0007)\end{array}$ & $\begin{array}{r}0,0001 \\
(0,0001)\end{array}$ & 0,71 \\
\hline Óleos & $\begin{array}{r}-0,0109 \\
(0,0013)\end{array}$ & $\begin{array}{r}0,0008 \\
(0,0001)\end{array}$ & 0,91 & $\begin{array}{r}-0,0111 \\
(0,0014)\end{array}$ & $\begin{array}{r}0,0008 \\
(0,0001)\end{array}$ & 0,91 \\
\hline Pão & $\begin{array}{r}-0,0817 \\
(0,0073)\end{array}$ & $\begin{array}{r}0,0060 \\
(0,0006)\end{array}$ & 0,96 & $\begin{array}{r}-0,0871 \\
(0,0076)\end{array}$ & $\begin{array}{r}0,0064 \\
(0,0006)\end{array}$ & 0,97 \\
\hline Presunto & $\begin{array}{r}0,0004 \\
(0,0004)\end{array}$ & $\begin{array}{r}0,0000 \\
(0,0000)\end{array}$ & 0,49 & $\begin{array}{r}0,0003 \\
(0,0004)\end{array}$ & $\begin{array}{r}0,0000 \\
(0,0000)\end{array}$ & 0,49 \\
\hline Queijos & $\begin{array}{r}0,0001 \\
(0,0012)\end{array}$ & $\begin{array}{r}-0,0001 \\
(0,0001)\end{array}$ & 0,67 & $\begin{array}{r}0,0001 \\
(0,0014)\end{array}$ & $\begin{array}{r}-0,0001 \\
(0,0001)\end{array}$ & 0,71 \\
\hline Sal & $\begin{array}{r}-0,0016 \\
(0,0002)\end{array}$ & $\begin{array}{r}0,0001 \\
(0,0000)\end{array}$ & 0,89 & $\begin{array}{r}-0,0017 \\
(0,0003)\end{array}$ & $\begin{array}{r}0,0001 \\
(0,0000)\end{array}$ & 0,89 \\
\hline Salsicha & $\begin{array}{r}-0,0012 \\
(0,0009)\end{array}$ & $\begin{array}{r}0,0001 \\
(0,0001)\end{array}$ & 0,66 & $\begin{array}{r}-0,0022 \\
(0,0010)\end{array}$ & $\begin{array}{r}0,0001 \\
(0,0001)\end{array}$ & 0,70 \\
\hline Tomate & $\begin{array}{r}-0,0058 \\
(0,0012)\end{array}$ & $\begin{array}{r}0,0004 \\
(0,0001)\end{array}$ & 0,86 & $\begin{array}{r}-0,0064 \\
(0,0013)\end{array}$ & $\begin{array}{r}0,0004 \\
(0,0001)\end{array}$ & 0,88 \\
\hline Peixe & $\begin{array}{r}-0,0139 \\
(0,0046)\end{array}$ & $\begin{array}{r}0,0010 \\
(0,0004)\end{array}$ & 0,84 & $\begin{array}{r}-0,0149 \\
(0,0047)\end{array}$ & $\begin{array}{r}0,0011 \\
(0,0004)\end{array}$ & 0,86 \\
\hline Mortadela & $\begin{array}{r}-0,0026 \\
(0,0007)\end{array}$ & $\begin{array}{r}0,0002 \\
(0,0001)\end{array}$ & 0,80 & $\begin{array}{r}-0,0026 \\
(0,0007)\end{array}$ & $\begin{array}{r}0,0002 \\
(0,0001)\end{array}$ & 0,81 \\
\hline
\end{tabular}

Fonte: Elaboração própria.

Obs. Os valores sombreados são significantes a pelo menos $5 \%$.

A análise da Tabela 2 mostra os estimadores do logaritmo da renda e do seu quadrado significantes em quase todos os casos. Na primeira coluna, amostra completa, o teste $t$ para o estimador da renda aceita a hipótese nula apenas para os seguintes produtos: 
carne de primeira, suíno, lingüiça, mandioca, manteiga, queijos, presunto e salsicha. Nos demais 28 casos o coeficiente da renda é significante a $5 \%$ ou a $1 \%$. Em todas as 36 equações, o teste $F$ de significância conjunta rejeita a $1 \%$ a hipótese de que os coeficientes da regressão são conjuntamente nulos. Os modelos mais bem ajustados são: açúcar, margarina, pão francês, café e feijão. Todos eles apresentam um $\mathrm{R}^{2}$ ajustado por graus de liberdade acima de 93\%. O pior ajuste foi observado para o item presunto, com um $\mathrm{R}^{2}$ ajustado por graus de liberdade de $49 \%$. Os demais produtos apresentam um ajuste de suas funções demanda superior a $60 \%$.

Quando a cidade de Goiânia é retirada da amostra (segunda coluna), não se observam grandes alterações nos resultados dos coeficientes. Entretanto, o $\mathrm{R}^{2}$ ajustado por graus de liberdade eleva-se na maioria das equações e os coeficientes da renda e da renda ao quadrado, na equação da salsicha, tornam-se significantes a 5\%.

Na Tabela 3 estão descritos os coeficientes das dummies de interação entre as regiões metropolitanas e o logaritmo neperiano da renda e da renda ao quadrado, tendo sido gerados a partir do modelo (7). A maioria dos coeficentes é significante a 5\%. Neste caso, os produtos para os quais o modelo tem pior aderência são: alho, banana, suíno, laranja, lingüiça, maionese, mandioca, presunto, queijos e salsicha. Todos estes produtos são consumidos por uma parcela da população com rendimento elevado. Desta forma, os pesos para a maioria destes produtos ficam muito próximos de zero, nas faixas de renda inferiores.

O baixo ajuste de alguns dos modelos acima se deve principalmente ao grande número de valores ausentes dos dados originais. A esses produtos foram imputados preços e gastos médios, o que dificulta a aderência do modelo.

A elasticidade-renda do modelo está abaixo derivada. Omitindo os índices da equação (4) chega-se à expressão abaixo:

$$
s_{i} \equiv \frac{p_{i} q_{i}}{X}=\sum \gamma_{i} \ln p_{i}+\beta_{i} \ln X+\lambda_{i}(\ln X)^{2}
$$

Derivando (6) em relação à renda e reorganizando os termos, obtêm-se:

$$
e\left(q_{i}, X\right)=\frac{\partial q_{i}}{\partial X} \frac{X}{q}=1+\frac{\beta_{i} X}{q_{i}}+2 \lambda_{i} \frac{X}{q_{i}} \ln X
$$

Ou

$$
e\left(q_{i}, X\right)=1+\frac{\beta_{i}+2 \lambda_{i} \ln X}{s_{i}}
$$

cuja fórmula é utilizada por Blundell, Pashardes e Weber (1993) para cálculo da elasticidade-renda no modelo QUAIDS. 


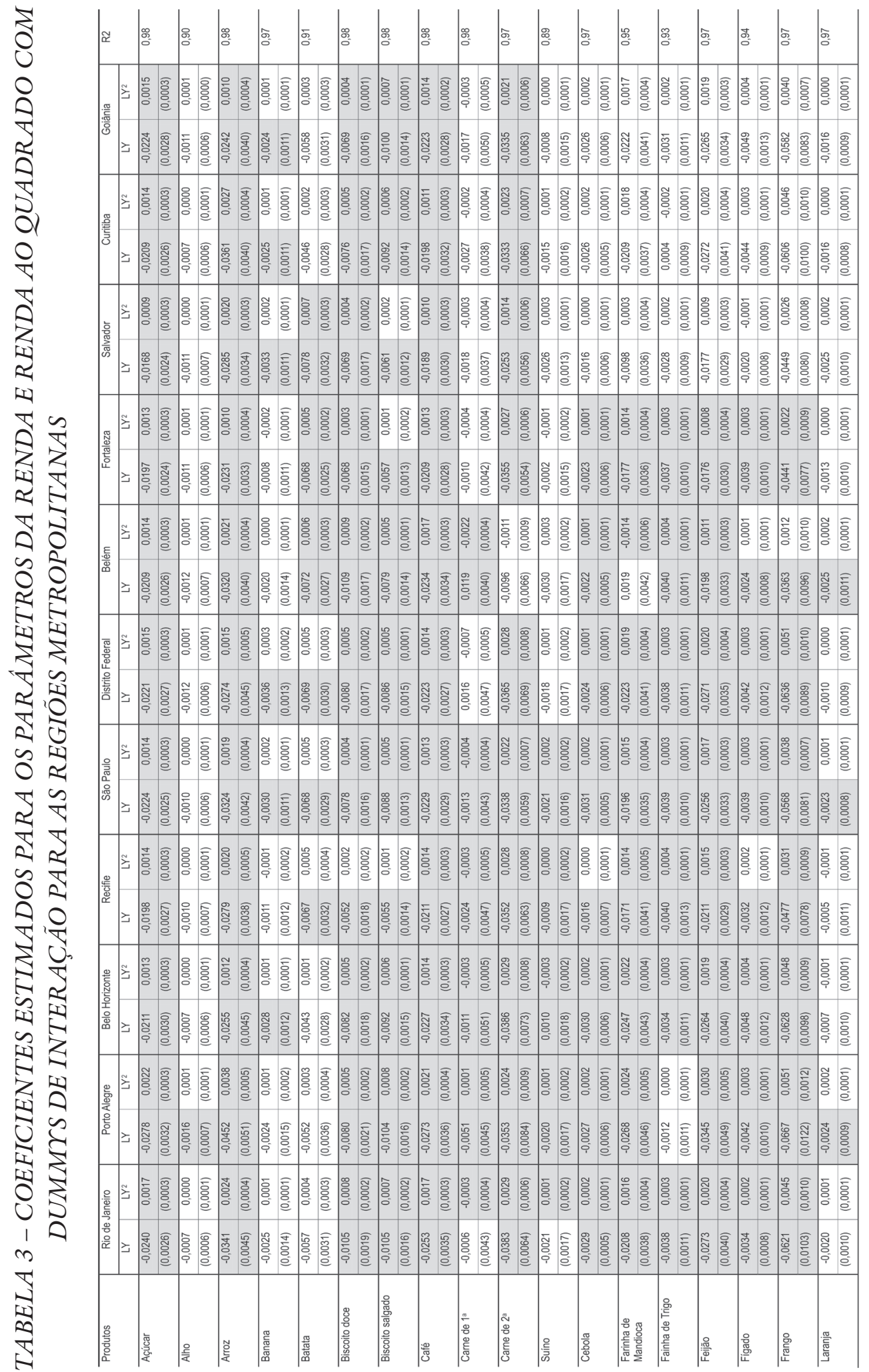




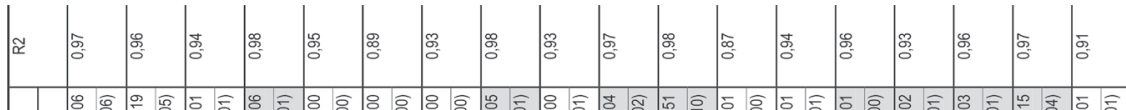

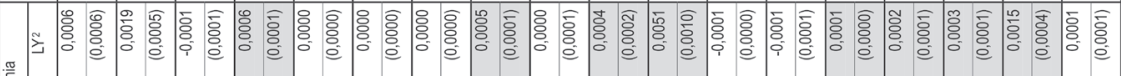

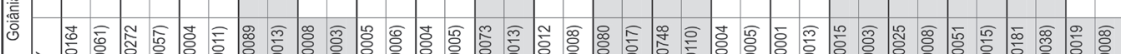

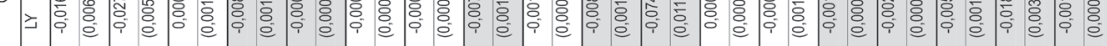

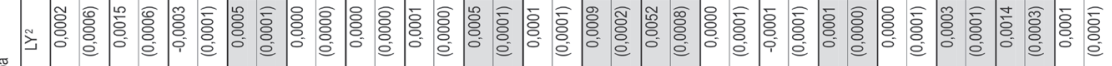

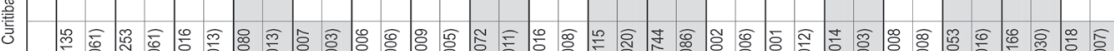

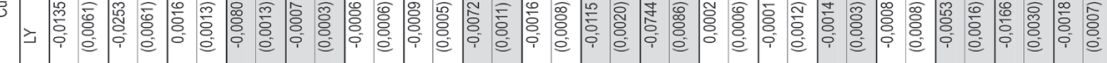

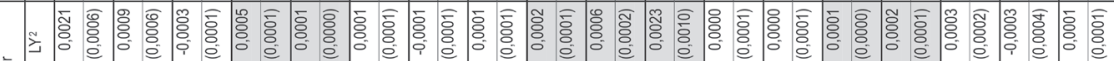

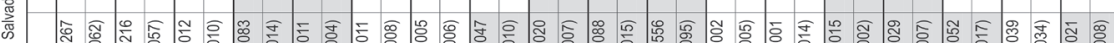

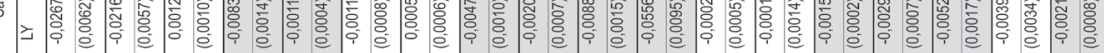

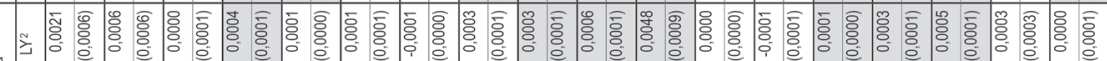

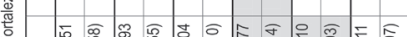

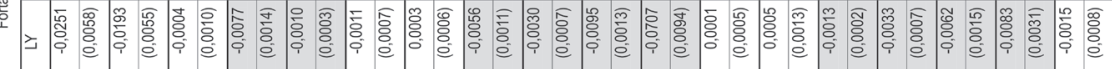

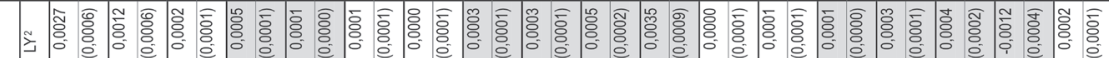

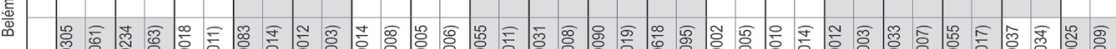
乙)

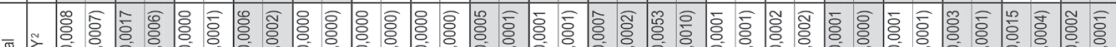
要

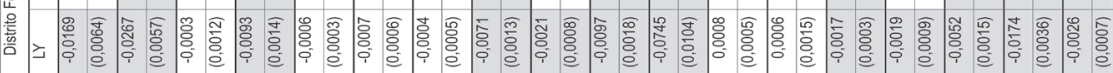

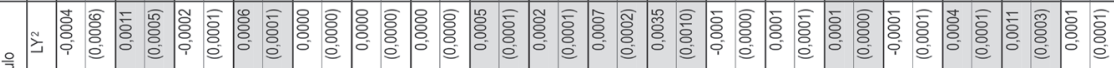

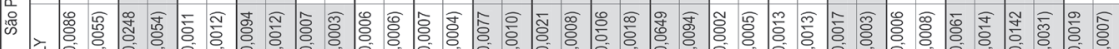

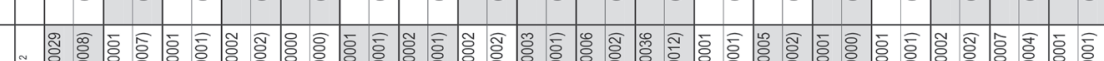

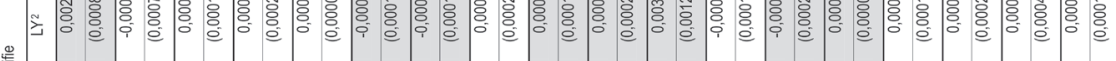

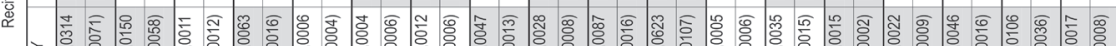
z

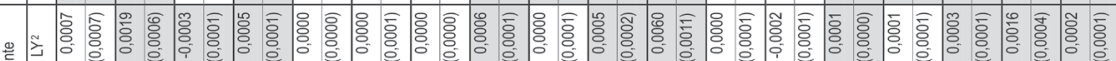

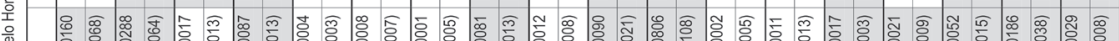

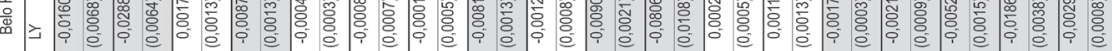

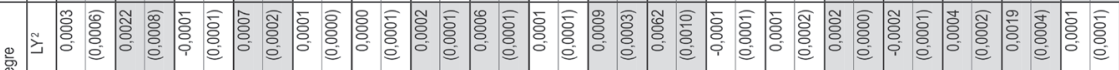

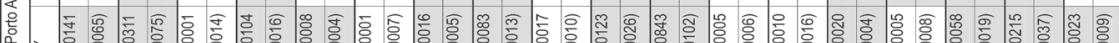

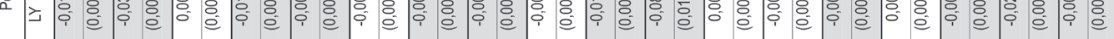

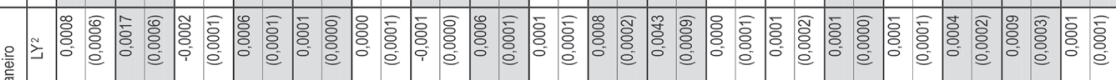

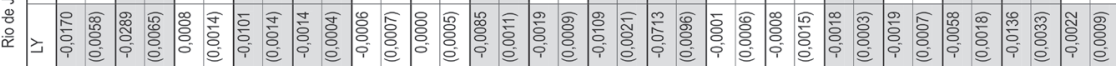

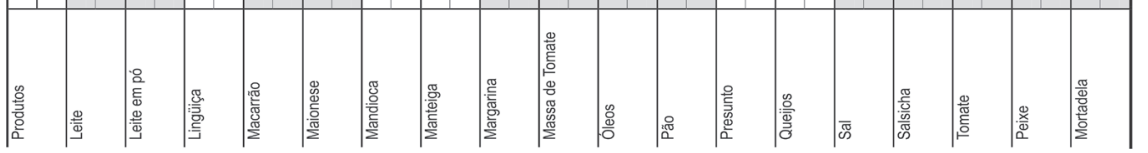




\subsection{Cálculo das Elasticidades e Análise dos Resultados}

No contexto do modelo QUAIDS, os valores para as elasticidades-renda foram calculados com base na equação $(9)$ derivada acima. Esta especificação empírica permite que as participações na renda, $s_{i k l}$, variem por faixa de renda e por regiões metropolitanas. Isto torna possível que as elasticidades se alterem dentro da amostra.

A Tabela 4 apresenta as elasticidades calculadas para: a renda total, com e sem Goiânia, e para primeira, quinta e décima faixa de renda, com os coeficientes estimados a partir do modelo (6). Para a décima faixa de renda não foi possível o cálculo da elasticidade de alguns produtos. Isto ocorre porque nesta faixa o peso de produtos como arroz ou sal é quase zero, o que fatalmente distorce o cálculo da elasticidade. $\mathrm{Na}$ Tabela 5 são apresentadas as elasticidades para as 11 regiões metropolitanas, calculadas a partir dos coeficientes estimados a partir do modelo (7).

TABELA 4 - ELASTICIDADE-RENDA PARA O BRASIL, BRASIL EXCLUSIVE GOIANIA: TOTAL E FAIXAS DE RENDA SELECIONADAS

\begin{tabular}{|c|c|c|c|c|c|c|c|c|}
\hline \multirow[b]{2}{*}{ Produtos } & \multicolumn{2}{|c|}{ Total } & \multicolumn{2}{|c|}{ Faixa de Renda 1} & \multicolumn{2}{|c|}{ Faixa de Renda 5} & \multicolumn{2}{|c|}{ Faixa de Renda 10} \\
\hline & Brasil & $\begin{array}{l}\text { Brasil s/ } \\
\text { Goiânia }\end{array}$ & Brasil & $\begin{array}{l}\text { Brasil s/ } \\
\text { Goiânia }\end{array}$ & Brasil & $\begin{array}{l}\text { Brasil s/ } \\
\text { Goiânia }\end{array}$ & Brasil & $\begin{array}{l}\text { Brasil s/ } \\
\text { Goiânia }\end{array}$ \\
\hline Açúcar & 0,1740 & 0,0717 & 0,3282 & 0,3248 & $-0,0839$ & $-0,0911$ & - & - \\
\hline Alho & 0,4243 & 0,3283 & 0,4711 & 0,4687 & 0,3432 & 0,3397 & - & - \\
\hline Arroz & 0,1420 & 0,1595 & 0,4345 & 0,4320 & 0,0762 & $-0,0815$ & - & - \\
\hline Banana & 0,4764 & 0,4476 & 0,6087 & 0,6075 & 0,4675 & 0,4660 & 0,0903 & $-0,1017$ \\
\hline Batata & 0,3395 & 0,3115 & 0,5734 & 0,5720 & 0,2317 & 0,2292 & 0,1210 & $-0,1413$ \\
\hline Biscoito Doce & 0,3695 & 0,2763 & 0,4637 & 0,4613 & 0,3306 & 0,3272 & - & - \\
\hline Biscoito Sal & 0,0601 & $-0,1230$ & 0,3194 & 0,3167 & 0,1869 & 0,1833 & - & - \\
\hline Café & 0,1204 & 0,0325 & 0,3376 & 0,3344 & 0,1236 & $-0,1303$ & - & - \\
\hline Carne de $1^{\mathrm{a}}$ & 0,6075 & 0,6689 & 0,7495 & 0,7496 & 0,6744 & 0,6745 & 0,4102 & $-0,4095$ \\
\hline Carne de $2^{\mathrm{a}}$ & 0,0735 & 0,1957 & 0,3119 & 0,3092 & 0,0777 & $-0,0823$ & 0,3436 & $-0,4516$ \\
\hline Suíno & 0,7369 & 0,7401 & 0,7902 & 0,7892 & 0,7184 & 0,7169 & 1,2397 & 1,2268 \\
\hline Cebola & 0,2694 & 0,2076 & 0,4270 & 0,4246 & 0,1289 & 0,1248 & - & - \\
\hline $\begin{array}{l}\text { Farınna de } \\
\text { Mandioca }\end{array}$ & 0,8698 & $-0,5737$ & 0,5931 & $-0,6019$ & 1,7031 & $-1,7235$ & - & - \\
\hline Farinha de Trigo & 0,4228 & 0,2682 & 0,5877 & 0,5860 & 0,2674 & 0,2641 & - & - \\
\hline Feijão & 0,0906 & $-0,0007$ & 0,2937 & 0,2902 & 0,2350 & $-0,2426$ & - & - \\
\hline Fígado & 0,1031 & $-0,1881$ & 0,1659 & 0,1619 & 0,0182 & 0,0126 & - & - \\
\hline Frango & 0,0571 & 0,0520 & 0,2536 & 0,2500 & 0,1784 & $-0,1854$ & - & - \\
\hline Laranja & 0,6648 & 0,5874 & 0,6703 & 0,6689 & 0,6397 & 0,6380 & - & - \\
\hline Leite & 0,5867 & 0,5909 & 0,7850 & 0,7844 & 0,5476 & 0,5466 & $-0,2651$ & $-0,2739$ \\
\hline Leite em pó & 0,1726 & $-0,3682$ & 0,1400 & 0,1357 & 0,4274 & $-0,4366$ & - & \\
\hline Lingüiça & 0,7417 & 0,6363 & 0,7973 & 0,7970 & 0,7490 & 0,7487 & 0,2779 & $-0,2809$ \\
\hline
\end{tabular}

(continua) 


\begin{tabular}{|c|c|c|c|c|c|c|c|c|}
\hline \multirow[b]{2}{*}{ Produtos } & \multicolumn{2}{|c|}{ Total } & \multicolumn{2}{|c|}{ Faixa de Renda 1} & \multicolumn{2}{|c|}{ Faixa de Renda 5} & \multicolumn{2}{|c|}{ Faixa de Renda 10} \\
\hline & Brasil & $\begin{array}{l}\text { Brasil s/ } \\
\text { Goiânia }\end{array}$ & Brasil & $\begin{array}{l}\text { Brasil s/ } \\
\text { Goiânia }\end{array}$ & Brasil & $\begin{array}{l}\text { Brasil s/ } \\
\text { Goiânia }\end{array}$ & Brasil & $\begin{array}{l}\text { Brasil s/ } \\
\text { Goiânia }\end{array}$ \\
\hline Macarrão & 0,3089 & 0,2291 & 0,4347 & 0,4319 & 0,1403 & 0,1352 & - & - \\
\hline Maionese & 0,7393 & 0,6740 & 0,6848 & 0,6832 & 0,7009 & 0,6988 & - & - \\
\hline Mandioca & 0,4723 & 0,4073 & 0,6415 & 0,6401 & 0,5637 & 0,5618 & 0,7431 & 0,7219 \\
\hline Manteiga & 0,7489 & 0,5727 & 0,7940 & 0,7933 & 0,6748 & 0,6738 & 0,7595 & 0,7553 \\
\hline Margarina & 0,1942 & 0,1452 & 0,2993 & 0,2959 & 0,0787 & $-0,0851$ & - & - \\
\hline Massa de Tomate & 0,4282 & 0,4727 & 0,6774 & 0,6764 & 0,3601 & 0,3582 & 0,3999 & $-0,4179$ \\
\hline Óleos & 0,3058 & 0,3520 & 0,4418 & 0,4393 & 0,2096 & 0,2055 & - & - \\
\hline Pão & 0,1940 & 0,1329 & 0,3954 & 0,3923 & 0,0498 & $-0,0565$ & - & - \\
\hline Presunto & 0,8528 & 0,9099 & 1,0322 & 1,0332 & 0,8697 & 0,8713 & 0,4754 & 0,4781 \\
\hline Queijos & 0,8187 & 0,7439 & 0,8968 & 0,8976 & 0,8618 & 0,8622 & 0,4935 & 0,4950 \\
\hline Sal & 0,0890 & 0,1152 & 0,4148 & 0,4121 & 0,1227 & $-0,1288$ & - & - \\
\hline Salsicha & 0,5516 & 0,4437 & 0,7786 & 0,7781 & 0,4015 & 0,4002 & 0,6578 & $-0,6689$ \\
\hline Tomate & 0,2047 & 0,1964 & 0,3653 & 0,3626 & 0,0966 & 0,0923 & - & - \\
\hline Peixe & 0,0495 & 0,0704 & 0,1367 & 0,1328 & 0,1759 & $-0,1820$ & 1,3727 & 1,3482 \\
\hline Mortadela & 0,2066 & 0,1106 & 0,4376 & 0,4349 & 0,1931 & 0,1885 & - & - \\
\hline
\end{tabular}

Fonte: Elaboração Própria.

Os dados da elasticidade-renda Brasil (Tabela 4) indicam que os produtos, na maioria, são bens normais, exceção apenas para farinha de mandioca e leite em pó, que se apresentam como bens inferiores. Uma análise regional (Tabela 5) mostra que a farinha de mandioca aparece como bem normal nas regiões do Norte e Nordeste, assim como no DF. Tais resultados vão bem ao encontro das evidências, pois além destas serem as regiões mais pobres do País, nelas o consumo da farinha de mandioca possui traços culturais fortes. Em Belo Horizonte tal produto comporta-se como bem inferior. Nas demais regiões - Rio de Janeiro, São Paulo, Curitiba, Porto Alegre e Goiânia - a participação deste produto na renda impossibilita o cálculo da elasticidade-renda.

O leite em pó possui um padrão semelhante ao da farinha de mandioca, comportando-se como um bem normal nos estados das regiões mais pobres: Norte e Nordeste. Para as demais regiões, o cálculo de sua elasticidada-renda fica prejudicado em razão do baixo peso destes produtos. Embora mais caro, este produto é de fácil conservação, permitindo, desta forma, seu consumo pelas famílias de baixa renda. Cabe notar que a elasticidade calculada por Menezes et al. (2002) assim como por Hoffmann (2000a) para este produto foi também negativa. Os resultados aqui alcançados são mais consistentes, na medida em que há uma queda da elasticidade quando se passa para uma faixa de renda mais elevada. 


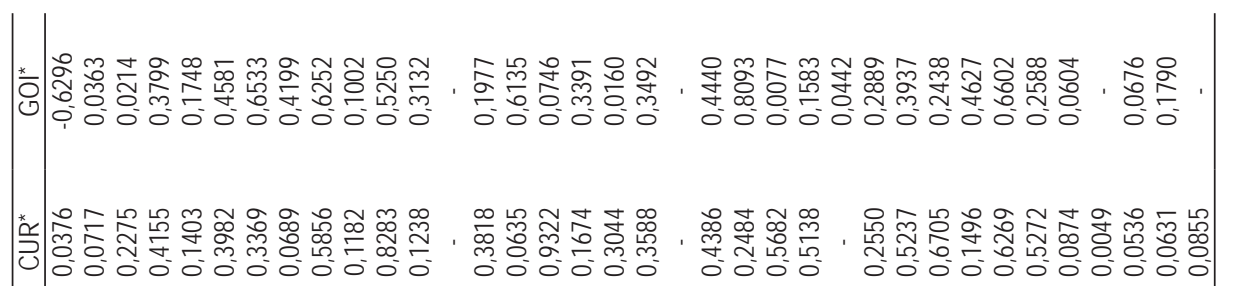

II

은

药

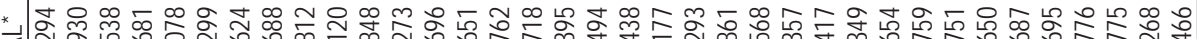

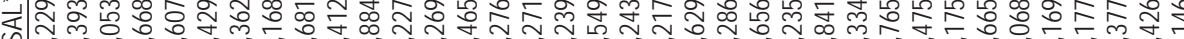

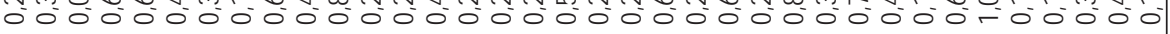

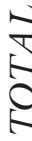

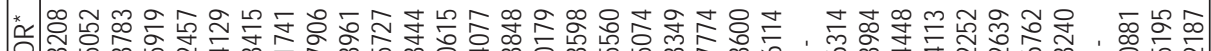

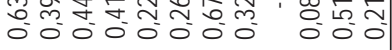
o.

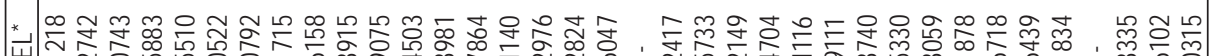

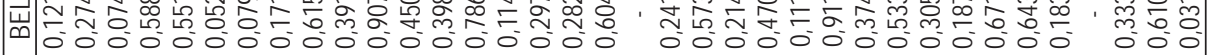

*

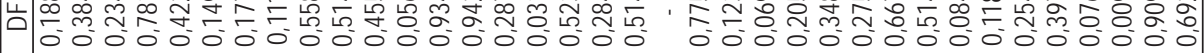

$\tilde{8}$

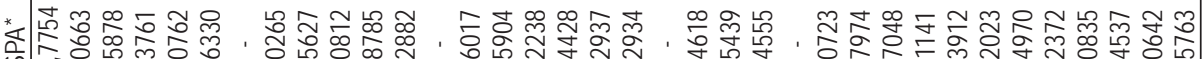

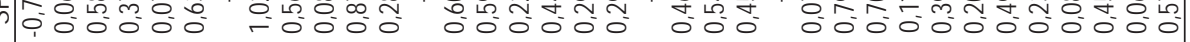

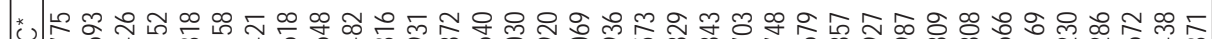

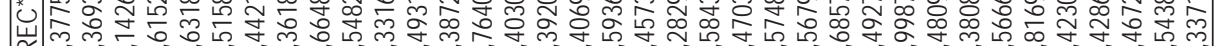

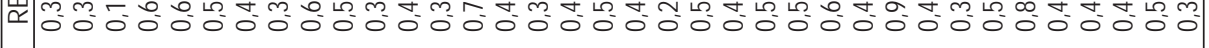

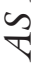

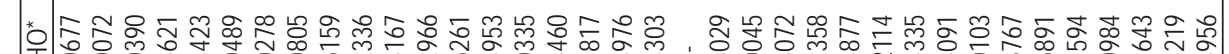

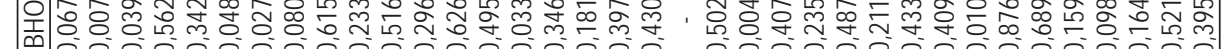

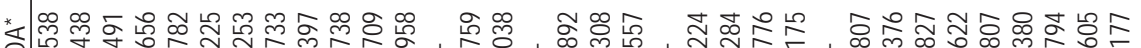

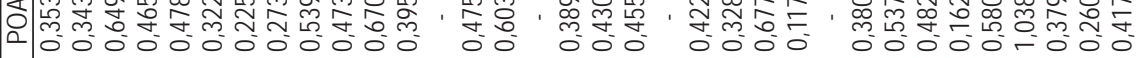

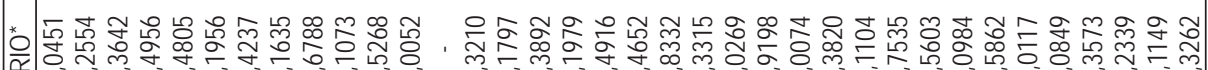

$$
\text { है }
$$

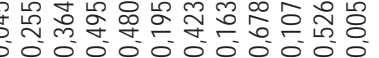

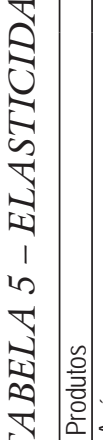

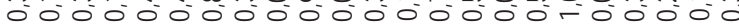

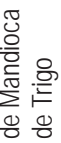


Dentre os bens normais, a elasticidade-renda da maioria dos produtos encontra-se de acordo com o esperado. Os produtos de elasticidade positiva mais baixa (inferiores a 0,1000) são: carne de segunda, feijão, frango, peixe e sal. Estes gêneros alimentícios são baratos e de consumo generalizado, de modo que suas aquisições não devem ter uma grande influência na renda. Comparando estes resultados com os de Hoffmann (2000a) e com os de Menezes et. al. (2002), nota-se que as elasticidades situam-se em patamares próximos, salvo no caso da massa de tomate e do arroz. Os bens normais que apresentam elasticidade-renda superior a 0,5500 são, em ordem decrescente: presunto, queijo, manteiga, lingüiça, maionese, suíno, laranja, carne de primeira e leite. Sabe-se que as carnes, as frutas e os derivados do leite são produtos cujo consumo cresce após ter sido atingido um determinado nível de renda, fato que o comportamento da elasticidade entre faixas de renda e entre as regióes metropolitanas vem confirmar. No caso das frutas, cabe observar que seus preços são relativamente superiores aos de seus substitutos.

A alta elasticidade-renda da mandioca pode ter duas explicações. Primeiro, pode haver problemas nos coeficientes estimados. Pelas Tabelas 2 e 3, seus coeficientes, além de muito baixo, só são significantes para a equação da primeira faixa de renda. De outra parte, este produto pode estar tendo um comportamento semelhante ao dos legumes, não sendo assumido como fonte de carboidratos, como arroz, pão e macarrão. Neste sentido, seria um substituto da batata e da cenoura, requerendo, ademais, um maior tempo de preparo.

Vale notar que as elasticidades no modelo 6 (sem interação) revelam-se, na maioria dos casos, coerentes com as expectativas. Isto fica claro quando se verifica que as elasticidades da carne de primeira e suína são bastante superiores à da carne de segunda e do frango. Situação similar se observa nos produtos lácteos, como queijos e manteiga, que exibem elasticidades elevadas ante o leite.

Quando se comparam aos resultados alcançados com os encontrados por Hoffmann (2000), verifica-se que as elasticidades aqui estimadas são superiores, sendo interessante salientar, no entanto, que o ordenamento dos produtos é bastante similar. Isto é, ainda que as elasticidades apresentem diferenças nas magnitudes, ambas distinguem os produtos de modo bastante semelhante. É importante também salientar que os cálculos executados por Hoffmann (2000a) não levam em consideração os preços dos produtos, e como esses variam entre as áreas urbanas, pode ocorrer uma subestimação dos valores das elasticidades entre elas. Outro ponto a destacar é que em seu trabalho Hoffmann (2000a) ordena as famílias pelo rendimento familiar e não pelo recebimento familiar per capita. 
Uma observação mais cuidadosa da Tabela 5 revela resultados satisfatórios para as elasticidades-renda das regiôes metropolitanas. Nas cidades do Norte e Nordeste a maioria dos produtos são bens normais, exceção apenas para a mortadela, mandioca, leite e salsicha. O primeiro aparece como bem inferior nas cidades de Belém e Salvador, pelo fato deste ser consumido principalmente pelas camadas mais pobres da população. Os três últimos apontam valores improváveis, principalmente em Belém e Fortaleza. Isto ocorre porque quando a participação do produto da cesta de consumo na renda é muito baixa (próxima à zero), o cálculo da elasticidade fica comprometido. Tal problema é observado com mais frequiência nas cidades das regióes Sul e Sudeste, uma vez que, sendo estas cidades mais ricas, a participação dos produtos da cesta na renda per capita é muito baixa. Por ser a mais rica, São Paulo é a cidade que mais apresenta bens inferiores. Para a maioria dos produtos, o DF apresenta um padrão de consumo bem próximo ao das cidades do Sul e Sudeste. A cidade de Goiânia, embora para a maioria dos produtos apresente elasticidades próximas à média, é uma área onde o número de informações não disponíveis foi muito elevado, vindo a prejudicar o cálculo das participações e, por conseguinte, das suas elasticidades.

Por fim, cabe observar que as elasticidades-renda são maiores na primeira faixa de renda e nas cidades do Nordeste-Norte do País, ou seja, nas famílias de menor poder aquisitivo e nas regiões metropolitanas mais pobres do País. A importância deste resultado está em evidenciar como um aumento de renda nas camadas inferiores eleva bastante o consumo dos gêneros alimentícios de primeira necessidade. Tal situação é também agravada pelo fato de a POF ser realizada apenas nas regióes metropolitanas, consideradas as áreas mais ricas. Observa-se que em $81 \%$ dos casos as elasticidadesrenda no Norte-Nordeste são superiores às estimadas no Sul-Sudeste.

\section{CONCLUSÕES}

O presente trabalho fornece três importantes contribuiçôes para se compreender um pouco melhor o comportamento da demanda por gêneros alimentícios no Brasil.

Primeiro, a análise foi realizada tendo por base os microdados da POF, que constituem uma base de dados rica, porém muito pouco explorada. A partir desta base selecionou-se uma cesta composta de 39 produtos alimentícios, calculando-se os valores de renda (recebimento mensal familiar per capita) e dos gastos em consumo com esses produtos para 10 classes de renda em cada uma das 11 regióes metropolitanas. A principal inovação do trabalho consistiu na construção dos preços implícitos a partir dos microdados. Estes foram obtidos recursivamente para as 10 classes de renda, proporcionando um banco de dados inédito e cujo efeito sobre o consumo até então não havia sido explorado. 
A segunda refere-se à utilização da extensão quadrática do modelo AIDS para descrever o comportamento da demanda por bens alimentícios no Brasil. Esta forma funcional permite que as elasticidades variem entre famílias, proporcionando uma maior precisão das estimações. Outra vantagem deste modelo é permitir que a amostra seja dividida, possibilitando que as elasticidades sejam estimadas por faixas de renda e por diferentes áreas.

Por fim, os resultados encontrados, em sua maioria originais, permitem aprofundar o conhecimento dos padrões de consumo entre os diversos extratos de renda, assim como entre regiões tão distintas como o Centro-Sul (Sul e Sudeste) e o Nordeste brasileiros. Esse conhecimento é vital para a formulação e desenho de políticas públicas que combatam os altos níveis de desigualdade vigentes na sociedade brasileira e que se refletem na apropriação desigual dos bens consumidos pelas famílias.

\section{REFERÊNCIAS BIBLIOGRÁFICAS}

Asano, S.; Fiuza, E. P. S. Estimation of the Brazilian consumer demand system. Rio de Janeiro: IPEA, 2001 (Texto para discussão, n. 793).

Aten, B. Cities in Brasil: an interarea price comparison. In: Heston and Lipsey (Eds.), International comparisons of income, output, and prices. Chicago: National Bureau of Economic Research, University of Chicago Press, 1999, p. 211-226.

Aten, B.; Menezes, T. Estimating price levels for low income groups: an application to Brazilian metropolitan areas. Working Paper on Expert Group Meeting on ICP. Disponível em: http://www.worldbank.org/data/icp.

Azzoni, C; Carmo, H; Menezes, T. Comparação da paridade do poder de compra entre cidades: aspectos metodológicos e aplicação ao caso brasileiro. Pesquisa e Planejamento Econômico, v. 33, n. 1, p. 91-126, abr. 2003.

Bertasso, Beatriz F. O consumo alimentar em regiões metropolitanas Brasileiras: análise da Pesquisa de Orçamentos Familiares/IBGE 1995/96. 2000. Dissertação (Mestrado), São Paulo.

Bianchini, Zélia M.; Albieri, Sonia. Uma revisão dos principais aspectos dos planos amostrais das pesquisas domiciliares realizadas pelo IBGE. Revista Brasileira de Estatistica, Rio de Janeiro, v. 60, n. 213, p. 7-23, jan/jul 1999.

Blundell, R.; Pashardes, P.; Weber, G. What do we learn about consumer demand patterns from micro data? The American Economic Review, v. 83, n. 3, p. 570597, June 1993.

Browning, M.; Meghir, C. The effects of male and female labor supply on commodity demand. Econometrica, v. 59, p. 925-951, July 1991. 
Castro, Paulo F.; Magalhães, Luís C. G. Recebimento e dispêndio das familias brasileiras: evidências recentes da Pesquisa de Orçamentos Familiares (POF) - 1995/1996. Brasília: IPEA, 1998, 37p. (Texto para Discussão, n. 614).

CEPAL. Brasil: Canastas basicas de alimentos y determinación de las lineas de indigencia e pobreza. Santiago: CEPAL, LC/L.532, 29 de diciembre de 1989, 43p.

Cyrillo, Denise C. et al. Tendência do consumo de alimentos e o Plano Real: uma avaliação para a Grande São Paulo. Planejamento e Politicas Públicas, IPEA, n. 16, dezembro de 1997.

Deaton, Angus; Muellbauer, John. An almost ideal demand system. The American Economic Review, v. 70, n. 3, p. 312-326, June 1980.

. Economics and consumer behavior. $2^{\mathrm{a}} \mathrm{ed}$. Cambridge University Press, 1983, 449 p.

Hoffmann, Rodolfo. Elasticidades-renda das despesas com consumo de alimentos em regiões metropolitano do Brasil em 1995-96. Informações Econômicas, v. 30, n. 2, fevereiro de 2000 .

. Elasticidades-renda das despesas e do consumo físico de alimentos no Brasil metropolitano em 1995-96. São Paulo, Agricultura em São Paulo, v. 47, n. 1, 2000 .

Kravis. B; Heston. A; Summers. R. World product and income: international comparisons of real gross product. Washington: The World Bank, 1982.

Menezes, T.; Silveira, S.; Magalhães, L.; Tomich, F.; Vianna, S. Gastos alimentares nas grandes regiões urbanas do Brasil: aplicação de um modelo AIDS com expansão quadrática aos microdados da POF 1995/96 do IBGE. 2002. Texto para discussão do IPEA.

Menezes, T.; Azzoni, C. Convergência de salários entre as regiões metropolitanas brasileiras: custo de vida e aspectos de demanda e oferta de trabalho. Pesquisa e Planejamento Econômico, v. 36, n. 3, dez. 2006.

Selvanathan, E. A.; Rao, D. S. P. Index Numbers. $4^{\text {th }}$ ed. Ann Harbor: University of Michigan Press, 1994.

Thomas, D.; Strauss, J.; Barbosa, M. M. T. Estimating the impact of income and prices changes on consumption in Brazil. New Haven (CT): Yale University, 1989 (Yale Economic Growth Discussion Paper, 589). 